\section{Perceptions by pregnant and childbearing-age women in southern Brazil towards teratogenic risk from medicines and radiotherapy}

\author{
Percepções de risco teratogênico de \\ medicamentos e radioterapia por gestantes e \\ mulheres em idade fértil no Sul do Brasil \\ Percepciones de riesgo teratogénico de \\ medicamentos y radioterapia en mujeres \\ embarazadas y en edad fértil en el sur de Brasil
}

Emilia da Silva Pons 1 Tatiane da Silva Dal Pizzol 1 Daniela Riva Knauth ${ }^{1}$

\author{
1 Programa de Pós-graduação \\ em Epidemiologia, \\ Universidade Federal do Rio \\ Grande do Sul, Porto Alegre, \\ Brasil. \\ Correspondence \\ E. S. Pons \\ Programa de Pós-graduação \\ em Epidemiologia, \\ Universidade Federal do Rio \\ Grande do Sul. \\ Rua Ramiro Barcelos 2400, \\ 2o andar, Porto Alegre, RS \\ 90035-003, Brasil. \\ emiliapons@yahoo.com.br
}

\begin{abstract}
Mistaken perception of teratogenic risk can keep pregnant women from using safe medicines. The current study analyzed women's concepts and perceptions towards teratogenic risk from medicines and exposure to radiotherapy during pregnancy. The quantitative data resulted from interviews with 287 pregnant and non-pregnant women. Two qualitative focus groups were conducted. No significant differences were observed between the two groups in terms of perceptions of teratogenic risk. Median perceptions of nonteratogenic exposures (paracetamol and metoclopramide) were close to the expected values, while higher values were found for teratogenic exposures (misoprostol and radiotherapy). The logic women used to estimate risk was classification of medicines as "strong" or "weak". Medicines perceived as "weak" by the women do not pose any teratogenic risk, as shown by the median perceptions close to the true values. Meanwhile, "strong" medicines were viewed as dangerous, thus explaining the high median perceptions of teratogenic exposures.
\end{abstract}

Teratogenic Dangers; Risk; Pharmaceutical Preparations; Pregnancy

\section{Resumo}

Percepção de risco teratogênico equivocada pode privar a gestante do uso de medicamentos seguros. O estudo analisou concepções e percepções de risco teratogênico de mulheres sobre o uso de medicamentos e exposição à radioterapia durante a gestação. Dados quantitativos resultaram da realização de entrevistas com 287 gestantes e não gestantes. Qualitativamente, dois grupos focais foram realizados. Não se observaram diferenças significativas nas percepções de risco teratogênico entre grupos. As medianas das percepções para as exposições não teratogênicas - paracetamol $e$ metoclopramida - foram próximas do valor esperado, e para as exposições teratogênicas - misoprostol e radioterapia - valores maiores foram encontrados. A lógica acionada pelas mulheres na estimação do risco é a da classificação dos medicamentos em fortes e fracos. Medicamentos percebidos pelas mulheres como fracos não apresentam risco, evidenciado pela aproximação das medianas ao valor esperado. Já medicamentos fortes são vistos como perigosos, justificando as altas medianas das exposições teratogênicas.

Perigos Teratogênicos; Risco; Preparações Farmacêuticas; Gravidez 


\section{Introduction}

Various epidemiological studies have documented the widespread use of prescription drugs during pregnancy. Although prevalence varies between studies, it is estimated that more than half of all pregnant women use at least one prescription drug during pregnancy 1,2,3,4.

Medication during pregnancy requires caution with drug choice and dosage, due to pharmacokinetic changes arising from the physiological alterations of pregnancy and teratogenic risk to the fetus 5 . For ethical reasons, pregnant women are usually excluded from clinical trials, and the assessment of teratogenicity in humans draws mainly on findings from observational epidemiological studies 6 . Evidence is thus scarce on the teratogenic risks of most drugs 7,8. Meanwhile, experts estimate that medicines contribute little to the overall incidence of birth defects 6

Mistaken perception of teratogenic risk can lead to non-use or lack of access to safe medicines, noncompliance with medication, or reluctance to adhere to medication during pregnancy, besides unnecessary distress to the pregnant woman and her family 9,10. Few studies have assessed the perceptions of pregnant and childbearing-age women towards teratogenic risk associated with the use of medicines, and these few studies have been performed in developed countries like Canada, Spain, and Norway 9,13. The results suggest that the perception of teratogenic risk is overestimated by pregnant women and the attending health professionals 9,10,11,12,14 . Our search in the indexed literature failed to find any studies on this issue performed in developing countries.

Most studies on risk perception associated with medicines were performed at teratogen information services or prenatal care services located in hospitals 9,11,12,14. Women who presented spontaneously to teratogen information services may show heightened concern regarding gestational risk and possibly greater risk perception. Meanwhile, pregnant women referred to these services by their physicians may have their risk perception modified, since the referral may cause anxiety, fear, and worry. Inversely, receiving care from a specialized service may give pregnant women greater ease of mind and thus mitigate their risk perception.

Risk perception involves several aspects that are difficult to measure. As some authors in the social sciences have pointed out, the ways by which a society rates and manages issues related to risk and danger depends on the cultural context 15,16 . The social sciences include an extensive discussion on risk and the importance of this cat- egory in current society 17,18 . However, our search in the MEDLINE, Embase, and LILACS databases failed to find any articles with a qualitative approach to teratogenic risk perception in relation to medicines.

Cultural characteristics, criminalization of abortion, difficulties in access to health services, deficient pharmacological training, precarious pharmaceutical care, and widespread self-medication can all influence risk perception. Thus, studies focused on pregnant women monitored by primary care in developing countries are crucial for understanding this phenomenon.

Therefore, the aim of this study was to analyze women's concepts and perceptions concerning teratogenic risk from medicines and exposure to radiotherapy during pregnancy, in the context of a developing country.

\section{Methodology}

The data analyzed here came from a study performed in Porto Alegre, Rio Grande do Sul State, Brazil, including a combination of quantitative and qualitative research methods. The study included women that attended three services in the municipal primary care system.

The quantitative data drew on structured interviews with childbearing-age women (15 to 49 years), grouped as pregnant versus nonpregnant.

For the quantitative phase, the sample was estimated using data available in the literature. In a Norwegian study $10,87.5 \%$ of the women correctly estimated the risk of birth defects in the general population (that is, the probability of a pregnant woman giving birth to a child with any major malformation). Thus, for purposes of calculation, the current study estimated that $70 \%$ of non-pregnant and $50 \%$ of pregnant participants would correctly assess the risk of birth defects in the general population. Considering $5 \%$ significance and $80 \%$ power, the estimated sample size was 103 women for each group. Study participants were consecutively recruited at three public health services that provide prenatal care.

Interviews were conducted by two trained pharmacists. Socio-demographic characteristics (age, race, schooling, income, and marital status), obstetric history (number of pregnancies, number of live births, abortions), and family history of birth defects (presence of a birth defect in the family, family relationship, type of malformation) were collected from all interviewees. Pregnant women also answered questions on the current pregnancy (gestational age, number of 
prenatal visits, and alcohol consumption, smoking, and health issues during pregnancy), and medicines used during pregnancy.

The quantitative data collection instrument used numerical questions to measure outcomes (perception of teratogenic risk). The question "In a population of healthy pregnant women, for every 100 babies that are born, how many do you think are born with some sort of physical or mental disability?" elicited a numerical answer from the respondent for the overall risk of birth defects. Likewise, the instrument measured the perception of teratogenic risk for medicines frequently used during pregnancy (paracetamol and metoclopramide), misoprostol, and radiotherapy. The questions included the most familiar trade names and indications for each drug and an explanation that radiotherapy is used for cancer treatment.

For the purposes of this study, the risk of birth defects in the general population was considered to be less than $3 \%$ 19. Paracetamol and metoclopramide were not considered teratogenic (risk of birth defects $\leq 3 \%$ ). Misoprostol and exposure to radiotherapy were considered teratogenic, with risk greater than $3 \% 7,20$.

The quantitative data were digitized and verified using Teleform 10.5 (Digital Vision, Highland Park, USA). Data analysis used PASW statistics 18 (SPSS Inc., Chicago, USA). Distribution of variables was verified using the Shapiro-Wilk test. Symmetrical variables are shown as means and standard deviations and asymmetrical variables as medians and interquartile range. Categorical variables are shown as absolute numbers and relative frequencies. Equality of proportions was evaluated using Pearson's chi-square test. The Mann-Whitney nonparametric test was used to compare medians between the pregnant and non-pregnant groups.

Perception of overall risk of birth defects in the general population was analyzed using Poisson regression with robust adjustment of variance. Variables were analyzed individually in the first step of the model. Variables that showed statistical significance, defined in this step as $\mathrm{p}<0.20$, were included in the multivariate model. Variables were not statistically significant at $\mathrm{p}<0.05$ in the multivariate model were removed one by one, while the main predictor variable, woman's status (pregnant versus non-pregnant), remained in the model.

The study's qualitative and quantitative phases were conducted concurrently in the same health clinics. Participants from prenatal care services were recruited in person or by telephone. Approximately 50 pregnant women, independently of gestational age, were invited to participate in the focus groups, resulting in two groups of 15 participants each.

The focus groups were conducted in meeting rooms at the clinics, without participation by the permanent staff. The discussion was moderated by two study investigators trained in anthropology and pharmacy, respectively.

Focus groups lasted 90 minutes on average. The discussion followed a script that included the main study questions, such as use of medicines during pregnancy, drugs that pose risks during pregnancy, potential problems for the pregnant woman and fetus, reasons why medicines can cause problems, other behaviors and substances that can be harmful during pregnancy, and sources of information on medicines taken by pregnant women. Qualitative topics were directly related to the questions addressed by the quantitative data collection instrument.

Focus groups were recorded on audio and transcribed in full by the study investigators. In the content analysis of the focus groups, the data were systematized into five central categories: (1) concepts concerning medicines, (2) classification of medicines, (3) strategies adopted in the use of medicines, (4) use of medicines during pregnancy, and (5) sources of information on medicines.

The study project was approved by the Ethics Research Committee of the Porto Alegre Municipal Health Department (case review n. 001.039589.10.2). All participants received an explanation of the research project and signed a free and informed consent form.

\section{Results}

Socio-demographic characteristics and use of medicines during pregnancy

From February to August 2011, 340 women were invited to participate in the study. Of these, 287 (144 pregnant and 143 non-pregnant women) agreed to participate and completed the interview.

Table 1 summarizes the main socio-demographic characteristics and variables related to obstetric history and family history of birth defects in the sample according to pregnant versus non-pregnant status. Most respondents were white, married or living with their partner, had 9 to 11 years of schooling, and had paid work. When compared to the non-pregnant group, more pregnant women were black or mixed-race, younger, and had less schooling and fewer children. There were also more married women in the pregnant group. Pregnant women that par- 
Description ( $\mathrm{n}$ and \% or median and interquartile range) of socio-demographic characteristics, obstetric history, and family history of birth defects, according to woman's pregnant versus non-pregnant status ( $n=287)$ *.

\begin{tabular}{|c|c|c|c|c|c|c|c|}
\hline \multirow[t]{2}{*}{ Characteristic } & \multicolumn{2}{|c|}{ Pregnant } & \multicolumn{2}{|c|}{ Non-pregnant } & \multicolumn{2}{|c|}{ Total } & \multirow[t]{2}{*}{ p-value ** } \\
\hline & n & $\%$ & n & $\%$ & $\mathrm{n}$ & $\%$ & \\
\hline Color/Race & & & & & & & 0.003 \\
\hline White & 86 & 59.7 & 110 & 76.9 & 196 & 68.3 & \\
\hline Non-white & 58 & 40.3 & 33 & 23.1 & 91 & 31.7 & \\
\hline Marital status & & & & & & & $<0.001$ \\
\hline Married/living with partner & 111 & 79.9 & 79 & 56.4 & 190 & 68.1 & \\
\hline Not living with partner & 28 & 20.1 & 61 & 43.6 & 89 & 31.9 & \\
\hline Schooling (years) & & & & & & & 0.024 \\
\hline$\leq 8$ & 41 & 28.5 & 23 & 16.1 & 64 & 22.3 & \\
\hline $9-11$ & 81 & 56.3 & 87 & 60.8 & 168 & 58.5 & \\
\hline$>11$ & 22 & 15.3 & 33 & 23.1 & 55 & 19.2 & \\
\hline Occupation & & & & & & & 0.913 \\
\hline Non-health-related paid work & 77 & 53.5 & 80 & 55.9 & 157 & 54.7 & \\
\hline Health-related paid work & 11 & 7.6 & 11 & 7.7 & 22 & 7.7 & \\
\hline Housewife & 30 & 20.8 & 25 & 17.5 & 55 & 19.2 & \\
\hline Unemployed & 26 & 18.1 & 27 & 18.9 & 53 & 18.5 & \\
\hline Religion & & & & & & & 0.064 \\
\hline None & 23 & 16.0 & 16 & 11.2 & 39 & 13.6 & \\
\hline Religious (practicing) & 54 & 37.5 & 73 & 51.0 & 127 & 44.3 & \\
\hline Religious (not practicing) & 67 & 46.5 & 54 & 37.8 & 121 & 42.2 & \\
\hline Parity & & & & & & & $<0.001$ \\
\hline 0 children & 70 & 48.6 & 39 & 27.3 & 109 & 38.0 & \\
\hline 1 child & 45 & 31.3 & 51 & 35.7 & 96 & 33.4 & \\
\hline$\geq 2$ children & 29 & 20.1 & 53 & 37.1 & 82 & 28.6 & \\
\hline Miscarriages & 20 & 13.9 & 23 & 16.1 & 43 & 15 & 0.722 \\
\hline Induced abortions & 7 & 4.9 & 8 & 5.6 & 15 & 5.2 & 0.989 \\
\hline Family history of birth defect & 15 & 10.4 & 22 & 15.4 & 37 & 12.9 & 0.280 \\
\hline Age (years) & 27 & $22-32$ & 31 & $24-38$ & 28 & $23-34$ & $0.021 * \star \star$ \\
\hline Per capita income (BRL) & 587.50 & $\begin{array}{l}300.00- \\
835.00\end{array}$ & 533.30 & $\begin{array}{l}327.00- \\
750.00\end{array}$ & 547.50 & $\begin{array}{l}300.00- \\
781.00\end{array}$ & $0.472 * \star \star$ \\
\hline
\end{tabular}

* Variation in the total number of women in the categories is due to missing data for the respective variables;

** Pearson's chi-square test;

*** Mann-Whitney nonparametric test.

ticipated in the focus groups were mostly 20 to 41 years of age and had an average of nine years of schooling. Most had paid work and were married or living with their partner.

Most of the pregnancies $(59.7 \%)$ were unplanned. Mean gestational age was 24.8 weeks ( $\mathrm{SD}=9.8$ ), and mean number of prenatal visits was 3.8 ( $\mathrm{SD}=2.9$ ). Approximately $20 \%$ of the pregnant women smoked during pregnancy, and $6.3 \%$ of these did not report any decrease in the number of cigarettes during pregnancy when compared to the six previous months. One out of eight pregnant women (12.5\%) reported some alcohol consumption during pregnancy, mostly less than one day a week.

Use of medicines during pregnancy was reported by $81.1 \%$ of the pregnant women. Of all the pregnant women that used some medication during pregnancy (116), 20 reported not having taken some prescribed drug due to fear that it might harm the fetus, while nine reported having altered the prescribed dose for the same reason. The drugs most frequently avoided by pregnant women were scopolamine butylbromide (Buscopan) and antiemetic drugs. Among the sources of information on medication used by pregnant 
women, the attending physician and package inserts were the most common (Table 2).

\section{Perception of teratogenic risk}

Figure 1 shows the medians and interquartile ranges for perceptions of teratogenic risk or risk of birth defects (without any exposure) in the general population, for each drug (paracetamol, metoclopramide, and misoprostol), and for exposure to radiotherapy. Median perceived risk for paracetamol $(\mathrm{Md}=3)$ and metoclopramide $(\mathrm{Md}=3.5)$ was lower than the perceived risk of birth defects in the general population $(\mathrm{Md}=8)$. Exposure to radiotherapy ( $\mathrm{Md}=42)$ and misoprostol $(\mathrm{Md}=50)$ were considered teratogenic, with far higher median values than those attributed to non-teratogenic exposures.

Table 3 shows the median values and interquartile ranges of perceived teratogenic risk for the entire sample and according to the woman's status (pregnant versus non-pregnant). Perception of teratogenic risk differed between the two groups, but without reaching statistical significance.

Table 4 shows the univariate models for risk perception of birth defects among the general population, according to socio-demographic characteristics and obstetric history and family history of birth defects. The models tested the following variables: self-reported skin color/ race, marital status, schooling, occupation, religion, parity, miscarriage and induced abortion, family history of birth defect, age, per capita income, and woman's status (pregnant versus non-pregnant). Self-reported skin color/race, age, and per capita income were statistically significant at $<0.20$ and were included in the multivariate model, along with the main predictor variable (pregnant versus non-pregnant status). In the final multivariate model, age ( $p=0.016$ ) and per capita income $(p=0.032)$ were positively associated with the correct perception of birth defects in the general population (data not shown in Table 4).

\section{Concepts and classification of medicines by pregnant women}

According to the qualitative data obtained from the focus groups, pregnant women strongly resisted the use of medicines in general, regardless of gestational period. This reaction appeared when they mentioned that they "don't like medicine", and also through reports of experiences from relatives who had over-used medication, as illustrated below:

"I never liked taking medicine, even before I was pregnant".

"At home, if I buy paracetamol, it's like candy. My husband and daughter gobble it up. I ask them, 'Does something hurt?' And they say, 'No, I'm

Table 2

Medication during current pregnancy $(n=143)$.

\begin{tabular}{|c|c|c|}
\hline Characteristic & $\mathbf{n}$ & $\%$ \\
\hline Use of medication during pregnancy & 116 & 81.1 \\
\hline \multicolumn{3}{|l|}{ Most widely used medicines * } \\
\hline Paracetamol & 83 & 70.9 \\
\hline Ferrous sulfate & 58 & 49.6 \\
\hline Metoclopramide & 30 & 25.6 \\
\hline Folic acid & 28 & 23.9 \\
\hline Antibiotics & 20 & 17.4 \\
\hline Discontinued prescribed drug fearing it might harm fetus & 20 & 17.2 \\
\hline Changed prescribed dose fearing it might harm fetus & 9 & 7.8 \\
\hline \multicolumn{3}{|l|}{ Sources of information on medicines * } \\
\hline Physician & 89 & 75.4 \\
\hline Package insert & 17 & 14.4 \\
\hline Neighbor, friend, or relative & 11 & 9.3 \\
\hline Internet & 11 & 9.3 \\
\hline Pharmacy & 10 & 8.5 \\
\hline Other & 3 & 2.5 \\
\hline
\end{tabular}

* The sum exceeds $100 \%$, because the pregnant woman may have responded to more than one category. 
Figure 1

Risk perception median values and interquartile ranges by the respondents, for general risk, for each medication, and for exposure to radiotherapy $(n=287)$.

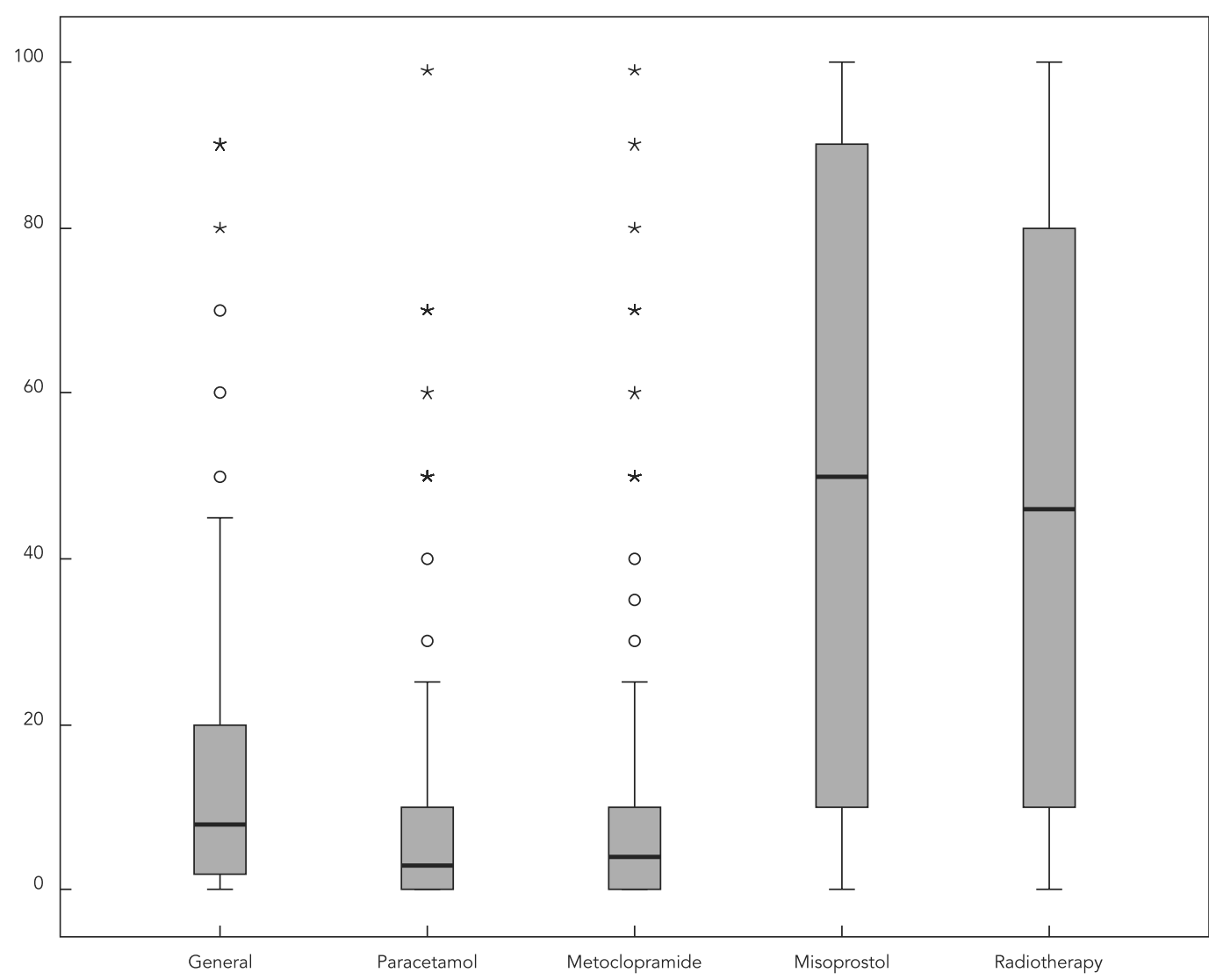

Note: the points are outliers or extreme values. The stars are extreme outliers, cases that have values more than three times the height of the boxes.

Table 3

Risk perception median values and interquartile ranges for overall risk of birth defects in the general population, for each drug, and for exposure to radiotherapy according to pregnant versus non-pregnant status and for the total sample.

\begin{tabular}{lccccc}
\hline & $\begin{array}{c}\text { “True" risk } \\
(\%)\end{array}$ & $\begin{array}{c}\text { Sample } \\
(\mathbf{n}=\mathbf{2 8 7})\end{array}$ & $\begin{array}{c}\text { Pregnant } \\
(\mathbf{n}=144)\end{array}$ & $\begin{array}{c}\text { Non-pregnant } \\
(\mathbf{n}=143)\end{array}$ & p-value * \\
\hline General & $\leq 3$ & $8(2-20)$ & $10(2.25-20)$ & $5(2-15)$ & 0.067 \\
Paracetamol & $\leq 3$ & $3(0-10)$ & $2(0-10)$ & $4(1-10)$ & 0.261 \\
Metoclopramide & $\leq 3$ & $3.5(0-10)$ & $3(0-10)$ & $5(0-10)$ & 0.406 \\
Misoprostol & $>3$ & $50(10-90)$ & $50(10-90)$ & $50(10-90)$ & 0.331 \\
Radiotherapy & $>3$ & $42(10-80)$ & $40(10-70)$ & $50(10-80)$ & 0.767 \\
\hline
\end{tabular}

* Mann-Whitney nonparametric test. 
Crude prevalence ratios for correct perception of teratogenic risk according to pregnant versus non-pregnant status, socio-demographic characteristics, obstetric history, and family history of birth defect $(n=287)$.

\begin{tabular}{|c|c|c|c|}
\hline Characteristic & PR & $95 \% \mathrm{Cl}$ & $p$-value * \\
\hline Pregnant & & & 0.357 \\
\hline No & 1.00 & - & \\
\hline Yes & 0.85 & $0.611-1.195$ & \\
\hline Color/race & & & 0.090 \\
\hline White & 1.00 & - & \\
\hline Non-white & 1.41 & $0.947-2.108$ & \\
\hline Marital status & & & 0.703 \\
\hline Not living with partner & 1.00 & - & \\
\hline Married/living with partner & 1.08 & $0.739-1.566$ & \\
\hline \multicolumn{4}{|l|}{ Schooling (years) } \\
\hline$\leq 8$ & 1.00 & - & \\
\hline $9-11$ years & 0.98 & $0.648-1.482$ & 0.922 \\
\hline$>11$ & 0.99 & $0.595-1.671$ & 0.992 \\
\hline \multicolumn{4}{|l|}{ Occupation } \\
\hline Non-health-related paid work & 1.00 & - & \\
\hline Health-related paid work & 1.35 & $0.811-2.237$ & 0.251 \\
\hline Housewife & 0.70 & $0.415-1.181$ & 0.182 \\
\hline Unemployed & 0.95 & $0.607-1.488$ & 0.823 \\
\hline \multicolumn{4}{|l|}{ Religion } \\
\hline None & 1.00 & - & \\
\hline Religious (practicing) & 1.02 & $0.599-1.750$ & 0.932 \\
\hline Religious (not practicing) & 1.10 & $0.647-1.876$ & 0.723 \\
\hline \multicolumn{4}{|l|}{ Parity } \\
\hline 0 children & 1.00 & - & \\
\hline 1 child & 1.24 & $0.838-1.840$ & 0.280 \\
\hline$\geq 2$ children & 1.08 & $0.702-1.662$ & 0.726 \\
\hline Miscarriage & & & 0.321 \\
\hline No & 1.00 & - & \\
\hline Yes & 0.76 & $0.444-1.305$ & \\
\hline Induced abortion & & & 0.937 \\
\hline No & 1.00 & - & \\
\hline Yes & 1.03 & $0.494-2.151$ & \\
\hline Family history of birth defect & & & 0.287 \\
\hline No & 1.00 & - & \\
\hline Yes & 0.72 & $0.400-1.312$ & \\
\hline Age (years) & 1.03 & $1.013-1.053$ & 0.001 \\
\hline Per capita income (BRL) & 1.00 & $1.000-1.001$ & 0.001 \\
\hline
\end{tabular}

95\% Cl: 95\% confidence interval; PR: prevalence ratio.

* Poisson regression with adjustment of robust variance.

just taking it before the pain comes'. They swallow it like candy. That's dangerous, isn't it?".

Two factors were related to the general rejection of medicines. The first was the dichotomy established between "natural" and "artificial", with medication assigned to the latter. The second, associated with the first, was the potential risk attributed to medication. In other words, as something artificial, all medicines were perceived as posing an inherent "danger" to the body. Women participating in the focus groups thus preferred products and practices regarded as "natural" - such as herbal teas, vitamins, and rest - as opposed to medicines. 
"I don't take medicine. The doctor told me to take Buscopan, the standard formula. But I didn't take it. Thank God my cramps went away. I just drink [herbal] tea. I try to stay calm when I realize I'm getting nervous, because I don't like taking medicine".

"I prefer natural things. If I can use natural treatment, I try to find the best option and take it. But medicine...I don't like it".

Besides the artificial nature of medications, the "danger" associated with their use was attributed to their potency. Thus, the women classified medicines according to their "strength". This appears to be related to both the drug's pharmacological class and its pharmaceutical form. Antibiotics, anti-inflammatories, antispasmodic agents, and tranquilizers, in addition to injections, were considered "strong". These medicines, considered strong in women's eyes, had to be avoided, especially during pregnancy.

Paracetamol stood out among the medicines classified as "weak". Classification of a medicine as weak was associated with availability and widespread use, and also with the fact that the drug was used by all age groups and in all situations. In other words, a "weak" drug was one that could always be used by everyone, both adults and children.

"I think paracetamol is weaker, right? That's what everybody says. Even the doctor prescribes it. But the strongest one must be ibuprofen, at least for me, because the doctor has never let me take it".

"I think Tylenol is stronger. It's made up of other ingredients. I think it's more dangerous than paracetamol alone".

"One of my brothers has a daughter who's HIVpositive, and once she took one of these medicines to find out what it was. They say she slept for two days. They say the medicine was strong. It was right after she discovered she had HIV".

The classification of medicines as either "strong" or "weak" outweighed their medical prescription. Thus, many respondents reported that they did not use some of the drugs prescribed by the physician, because they considered them too strong, especially during pregnancy, as inferred from the following quotes:

"I consulted a psychiatrist, because I was worried. She gave me a lot of medicine, too, but I haven't taken any of it so far. She asked me, 'Haven't you taken your medication?' I said, 'No, doctor, I haven't'. I ended up not taking it. I feel really nervous, but it's useless... I know they'll give me some medicine, and I won't be able to take it. I just can't make myself take it".

"I commented to the doctor that I had heartburn, and she said, 'Okay, I'll prescribe an antacid for you'. I said, 'No, thanks, doctor. It'll go away by itself"'.

The refusal to take some prescribed medications was justified by their purported effects due to their potency, expressed through the idea of feeling ill. Hence, whether they were considered "strong" or "weak", as reported in the women's discourse, medicines were only used in situations perceived as extremely uncomfortable.

"I'm really afraid of taking medicine. The medicine I take sometimes is paracetamol. But the pain has to be really strong, otherwise I don't take it".

"Even if I had a serious disease, God forbid, I wouldn't take any medication, except if I were hospitalized, on an IV drip".

"The doctor told me that Yasmin [an oral contraceptive] wasn't that weak. So in my last pregnancy I wanted to have a tubal ligation so I wouldn't have to take those medicines anymore".

The notion that medicines, especially "strong" ones, could have unwanted effects on the woman's system led to feelings of fear. This was the reason (fear plus difficulty in weighing the risks and benefits of medicines) why women often avoided taking medicines, even those indicated to promote normal fetal development, as illustrated by the following quote:

"They gave me some other medicine for the baby's normal development. I took one pack. Later I got this notion into my head ... that I wasn't so sure. So I didn't take it anymore, because I hadn't taken it in my other pregnancies. I wasn't familiar with it. The doctor said it was normal to take it. Another doctor told me to take it, because it was for the baby's normal development".

Vitamins and vaccines were more acceptable to the women participating in the focus groups, since they were not considered "drugs". Ferrous sulfate was highlighted in the vitamins class, since its use was acknowledged as important during pregnancy.

\section{Concepts and strategies for assessing risk from medication during pregnancy}

Some medicines and exposures, such as misoprostol, radiotherapy, and other substances considered abortive (wormwood tea, cinnamon tea, and linseed oil) were perceived by the participants as teratogenic. Although women showed difficulty in accurately weighing the risk, there was a perception that these substances and exposures can cause important sequelae to the fetus, as illustrated below:

"I've heard of Cytotec [misoprostol]... I've heard of it, but I'm not directly familiar with any cases. I've heard of people who have taken it. It 
worked for some women, but there's always a risk, isn't there? You don't know what might happen. If it doesn't work, and even if the baby survives, you don't know what the risk is for the baby, do you?".

"It causes malformations, doesn't it? I have an aunt... my cousin was born without this bone here. She says she took a lot of medicine, even to cause an abortion, during her pregnancy. The abortion ended up not happening, and my cousin was born with one side of her face completely malformed".

" $X$-rays, $x$-rays are all I hear about. People say they're the most dangerous of all".

Risk was usually assessed on the basis of close experiences or those that had occurred with relatives. Generic information on a potential risk was available, but since it was not accurate and did not have an identifiable source ("they say"), it did not allow for accurate risk assessment. Therefore, the potential risk was generalized for the product or exposure, not for the dose.

In the study context, and given the low accuracy of information, the women adopted four different strategies to decide whether to take medicines during pregnancy:

a) They requested explanation from the physician on a given drug: "It depends on the medicine. In the case of very strong medicine, I always ask first".

b) They did not take medicines they considered "dangerous": "I never liked medicine, even before I was pregnant. I said to the doctor, 'No, doctor, I'm not taking it.' She said, 'It's alright, take it, it won't do any harm.' So I said, 'Okay, I'll take it.' But of course I didn't take the drug she prescribed. I don't want to cause problems, right? But there was no way I was going to take that medicine".

c) They used medicines that can also be taken by children: "I always think that if my son can take paracetamol, I can take paracetamol. I'm not going to take anything else, because it can hurt my baby inside here, can't it?" [pointing to her womb] d) They check the information on the package insert: "We check the package insert to learn about the reaction that can happen ifyou take... [a given drug], and when I see the doctor I ask her whether I can take it or not".

Although requesting information from physicians was one of the strategies used by women, they reported a lack of consensus among different healthcare professionals regarding the potential risks of medicines during pregnancy, as illustrated below:

"I think there should be a little more information at the clinic, like on posters. There should be more posters on medications. Because one doctor says one thing, then another says something else, and then you ask a pharmacist, and he either doesn't know what to tell you or says something different. Everybody tells you something different, so you never know what's right. Even when the doctor gives you a prescription, she isn't always right. I think there should be more information on the medicines, more posters explaining, for example, that not everyone says, 'Oh, I'm going to take it and that's that,' because people don't always read the package insert, period. There should be more information".

Thus, although they identified sources and healthcare staff to whom they could resort to obtain more information, the difficulty evaluating which information was correct and whom they should believe still persisted among the women.

\section{Discussion}

In the current study, the emic classification of drugs as strong or weak (which influenced their use) did not depend on the woman's stage in life. The fact that women shared this rationale may explain why no significant differences were found between pregnant and non-pregnant women in terms of perceived teratogenic risk. Sanz et al. ${ }^{9}$, in a study in Spain, found a statistically significant difference between pregnant and non-pregnant women for some medicines. However, according to the authors, this difference may have been due to the methodological procedures used in the study (Visual Analogue Scale, identified by the authors themselves as subject to limitations). A study in Norway by Nordeng et al. 10 compared pregnant women to women with at least one child and found similar risk perceptions between the two groups.

In the current study, the risk of birth defects perceived by women for non-teratogenic medications (paracetamol and metoclopramide) was close to the true value. However, the perceived risk of birth defects in the general population was slightly higher than the expected 3\%. Meanwhile, women's perception of the teratogenic potential of misoprostol and radiotherapy was high, clearly indicating that they recognized the teratogenic risks of this substance and exposure. In relation to misoprostol, this heightened perception may be due to the fact that the drug is widely used in Brazil to induce abortion. As an abortive agent, misoprostol was classified by the women as "strong" and thus subject to high risk. Abortion is illegal in Brazil, and when used to interrupt pregnancy, misoprostol is usually purchased on the underground market.

The women estimated teratogenic risk dichotomously as "strong" or "weak". According to this logic, a drug perceived as "weak" was sup- 
posedly harmless. Inversely, "strong” medicines potentially caused negative effects, depending on the drug's "strength". This rationale explains the perception of low risk for non-teratogenic drugs and high risk for teratogenic drugs and exposures, making this a classification of extremes, of "all-or-nothing".

Our results differed from those of previous studies that found overestimation of risk, even for non-teratogenic drugs 9,10,11,12,13,19. This difference may be partly due to the fact that most of the previous studies included women that used specialized services (including those providing teratogen counseling), while our study sample included women attending primary care clinics. Another factor that may have contributed to the agreement between women's perceived risk and the true risk values was the use of questions with numerical risk estimation rather than Visual Analogue Scales. For the study sample, there was no agreement between the two techniques for measuring risk perception (unpublished observation).

Study participants' difficulty in accurately assessing the risk of teratogenic substances and exposures, observed in our study and reported in previous studies, may involve skills in mathematical logic. The international literature refers to such skills as numeracy, defined as a dimension of literacy related to the ability to understand numbers 21,22 . Recent health studies have highlighted the association between difficulties in handling numerical concepts and understanding and grasping health information 23. Although our study did not evaluate numeracy, we suggest that perception of teratogenic risk is directly related to understanding mathematical concepts, especially those involving probability and proportion.

However, although an association can be expected between the grasp of mathematical concepts and schooling, studies have not identified a direct association between risk perception and education 24 . Our study, in which $23 \%$ of the women had up to 8 years of schooling, also failed to find such an association. Lipkus et al. 25 evaluated numeracy skills in a sample of individuals with higher levels of schooling and found that $40 \%$ of the participants were unable to solve basic probability problems or to convert percentages into proportions. These findings indicate that such mathematical concepts are grasped not only through formal education, but also through the daily use of such logic.

Scientific risk classification differs from the logic used by the lay public to assess risk. Furthermore, there is no agreement on risk percep- tion between scientists from different fields 26 . This lack of consensus among scientists is transferred to professionals, including those in healthcare, as shown in a study by Sanz et al. 9 in which physicians overestimated the teratogenic risk of several drugs. Participants in our study reported a lack of consensus among health professionals regarding the risk of medicines during pregnancy, causing uncertainty in patients. Although respondents recognized physicians as a potential source of orientation, the lack of consensus often led them resort to other strategies to reach a decision on taking medication, such as prioritizing family or close personal experiences and information from package inserts. Fewer women in our sample resorted to the pharmacist as a source of information. Comparatively, according a study by Nordeng et al. 10, the sources of information most frequently used by women were the physician, package insert, and pharmacy.

As opposed to scientific logic concerning risk, based on calculating probabilities and making future projections, women's perceptions of the risk of birth defects was based much more on actual, real-time situations. Their perception was thus much closer to the category of "danger" 15. Given their difficulty in handling probabilistic logic, the women calculated risk based on the experience of family and friends. Birth defects were part of the women's experience, and they were thus expected to occur "naturally" - most of the women had already seen or had direct or indirect contact with children with birth defects. This expected presence of children born with malformations appeared in the study's data, where the risk of birth defects in the general population was situated in an intermediate position, between the perceived risk of "weak" and "strong" medicines.

The results discussed above should be considered within the context of the current study: the sample size, the fact that it was not probabilistic, and the number of focus groups may present limitations. We thus emphasize the importance of further studies combining qualitative and quantitative research techniques in order to confirm and extend the findings presented here.

Finally, our results suggest that interventions designed to provide more information on the use of medications during pregnancy should consider that women adopt their own logic to classify medicines. Print materials are essential, containing more accurate information on the use of medications during pregnancy and incorporating more accessible numerical explanations on teratogenic risk estimation. 


\section{Resumen}

Percepción equivocada del riesgo teratogénico puede privar a las embarazadas de la utilización de medicamentos seguros. En este estudio se analizan las concepciones y la percepción de riesgo teratogénico de mujeres con respecto al uso de medicamentos y exposición a la radioterapia durante el embarazo. Los datos cuantitativos resultan de la administración de entrevistas a 287 mujeres embarazadas y no embarazadas; los cualitativos, de dos grupos focales. No se encontraron diferencias significativas en la percepción de riesgo entre los grupos. Las medianas para la percepción de riesgo a las exposiciones no teratogénicas resultaron cerca del valor esperado, mientras que para las exposiciones teratogénicas se encontraron valores más altos. La lógica usada por las mujeres para estimar el riesgo clasifica los medicamentos en fuertes y débiles. Aquellos percibidos como débiles no suponen riesgo (lo que se evidencia por la aproximación de las medianas al valor real). Por otra parte, los fuertes son vistos como peligrosos, lo que jus tifica las medianas altas para los riesgos teratogénicos.

Peligros Teratogénicos; Riesgo; Preparaciones Farmacéuticas; Embarazo

\section{Contributors}

E. S. Pons and D. R. Knauth participated in elaborating the research project, data analysis and interpretation, and writing of the article. T. S. Dal Pizzol collaborated in the elaboration of the project, data interpretation, and critical revision of the article's intellectual content.

\section{Acknowledgments}

The authors wish to thank the Capes research funding agency for providing a Master's scholarship to Emilia da Silva Pons.

\section{References}

1. Andrade SE, Gurwitz JH, Davis RL, Chan KA, Finkelstein JA, Fortman K, et al. Prescription drug use in pregnancy. Am J Obstet Gynecol 2004; 191:398407.

2. Engeland A, Bramness JG, Daltveit AK, Ronning M, Skurtveit S, Furu K. Prescription drug use among fathers and mothers before and during pregnancy: a population-based cohort study of 106,000 pregnancies in Norway 2004-2006. Br J Clin Pharmacol 2008; 65:653-60.

3. Gagne JJ, Maio V, Berghella V, Louis DZ, Gonnella JS. Prescription drug use during pregnancy: a population-based study in Region Emilia-Romagna, Italy. Eur J Clin Pharmacol 2008; 64:1125-32.

4. Riley EH, Fuentes-Afflick E, Jackson RA, Escobar GJ, Brawarsky P, Schreiber M, et al. Correlates of prescription drug use during pregnancy. J Womens Health (Larchmt) 2005; 14:401-9.

5. Loebstein R, Koren G. Clinical relevance of therapeutic drug monitoring during pregnancy. Ther Drug Monit 2002; 24:15-22.

6. De Santis M, Straface G, Carducci B, Cavaliere AF De Santis L, Lucchese A, et al. Risk of drug-induced congenital defects. Eur J Obstet Gynecol Reprod Biol 2004; 117:10-9.
7. Briggs GG, Freeman RK, Yaffe SJ. Drugs in pregnancy and lactation: a reference guide to fetal and neonatal risk. Philadelphia: Lippincott Williams \& Wilkins; 2011.

8. Shepard TH. Catalog of teratogenic agents. Baltimore: Johns Hopkins University Press; 1992.

9. Sanz E, Gómez-López T, Martínez-Quintas MJ. Perception of teratogenic risk of common medicines. Eur J Obstet Gynecol Reprod Biol 2001; 95:127-31.

10. Nordeng H, Ystrom E, Einarson A. Perception of risk regarding the use of medications and other exposures during pregnancy. Eur J Clin Pharmacol 2010; 66:207-14.

11. Koren G, Bologa M, Long D, Feldman Y, Shear NH. Perception of teratogenic risk by pregnant women exposed to drugs and chemicals during the first trimester. Am J Obstet Gynecol 1989; 160:1190-4.

12. Mazzota P, Magee LA, Maltepe C, Lifshitz A, Navioz Y, Koren G. The perception of teratogenic risk by women with nausea and vomiting of pregnancy. Reprod Toxicol 1999; 13:313-9. 
13. Pole M, Einarson A, Pairaudeau N, Einarson T, Koren G. Drug labeling and risk perceptions of teratogenicity: a survey of pregnant Canadian women and their health professionals. J Clin Pharmacol 2000; 40:573-7.

14. Koren G, Levichek Z. The teratogenicity of drugs for nausea and vomiting of pregnancy: perceived versus true risk. Am J Obstet Gynecol 2002; 186(5 Suppl Understanding):S248-52.

15. Douglas M, Wildavsky A. Risk and culture: an essay on the selection of technological and environmental dangers. Berkeley: University of California Press; 1984.

16. Hofstede G. Cultures and organizations: software of the mind. New York: McGraw-Hill; 1991.

17. Beck U. Risk society: towards a new modernity. London: Sage Publications; 1992.

18. Giddens A. A modernity and self-identity: self and society in the late modern age. Cambridge: Polity Press; 2002.

19. Bonari L, Koren G, Einarson TR, Jasper JD, Taddio A, Einarson A. Use of antidepressants by pregnant women: evaluation of perception of risk, efficacy of evidence-based counseling and determinants of decision-making. Arch Women's Ment Health 2005; 8:214-20.

20. Arnon J, Meirow D, Lewis-Roness H, Ornoy A. Genetic and teratogenic effects of cancer treatments on gametes and embryos. Hum Reprod Update 2001; 7:394-403.
21. Peters E, Hibbard J, Slovic P, Dieckmann N. Numeracy skill and the communication, comprehension, and use of risk-benefit information. Health Aff (Millwood) 2007; 26:741-8.

22. Valverde G, Näslund-Hadle E. The state of numeracy education in Latin America and the Caribbean. Washington DC: Inter-American Development Bank; 2010.

23. Conover EA, Polifka JE. The art and science of teratogen risk communication. Am J Med Genet Part C Semin Med Genet 2011; 157:227-33.

24. Sjöberg L. The methodology of risk perception research. Qual Quant 2000; 34:407-18.

25. Lipkus IM, Samsa G, Rimer BK. General performance on a numeracy scale among highly educated samples. Med Decis Making 2001; 21:37-44.

26. Polifka JE, Faustman EM, Neil N. Weighing the risks and the benefits: a call for the empirical assessment of perceived teratogenic risk. Reprod Toxicol 1997; 11:633-40.

Submitted on 21/Mar/2013

Final version resubmitted on 12/Nov/2013

Approved on 25/Feb/2014 